\title{
Using Dung to Estimate Gorilla Density: Modeling Dung Production Rate
}

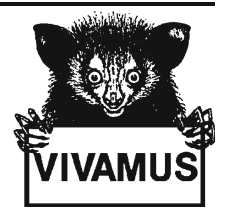

\author{
Angelique F. Todd • Hjalmar S. Kuehl • \\ Chloé Cipolletta • Peter D. Walsh
}

Received: 13 September 2007 / Accepted: 14 September 2007 /

Published online: 5 April 2008

(C) The Author(s) 2008

\begin{abstract}
There is an urgent need for information on western gorilla population sizes and distribution to improve present and plan future conservation actions. Researchers traditionally have estimated gorilla densities on the basis of nest counts despite demonstrated variation in nest production and decay rates. The variation may lead to large biases in estimates of gorilla abundance. We investigated the use of an alternate index of gorilla abundance, via defecation data collected from habituated gorillas at Bai Hokou, Central African Republic. Our sample of 274/370 defecation events/dung piles produced a production rate of ca. 5 dung piles/d: comparable to previous estimates based on much smaller sample sizes. Heuristic models that failed to account for imperfect dung pile detection produced a lower defecation rate estimate than that of a maximum likelihood model that explicitly modeled detection probability. Generalized linear modeling (GLM) showed that dung pile production rate was strongly linked to rainfall, suggesting that failure to correct for seasonal variation in dung pile production rates could lead to substantial biases in gorilla abundance estimates. In our study, failing to distinguish between the number of defecation events and the number of dung piles produced would lead to a $c a .31 \%$ overestimate of true gorilla numbers. The use of dung as an index of gorilla abundance shows potential, but more fieldwork and modeling on seasonal variation in dung production rates is required.
\end{abstract}

Keywords dung $\cdot$ gorilla density $\cdot$ model $\cdot$ survey

\footnotetext{
A. F. Todd $(\bowtie) \cdot$ H. S. Kuehl $\cdot$ P. D. Walsh

Department of Primatology, Max-Planck-Institute for Evolutionary Anthropology,

04103 Leipzig, Germany

e-mail: todd@eva.mpg.de

C. Cipolletta

World Wildlife Fund, Dzanga-Sangha Project, BP 1053, Bangui,

Central African Republic
} 


\section{Introduction}

Throughout Central Africa, western gorilla populations are seriously threatened by deforestation, the bushmeat trade, and diseases such as Ebola hemorrhagic fever. Ape populations have declined drastically in the last 2 decades (Walsh et al. 2003); a recent outbreak of Ebola in Congo caused a massive die-off (ca. 5000 gorillas: Bermejo et al. 2006). However, despite increased conservation efforts, only limited information is available on how many western gorillas remain or their distribution. The information is urgently needed and fundamental to assess and to improve the efficiency and effectiveness of future conservation actions.

The lack of information results largely from the inherent difficulties of monitoring individuals in dense forests. Directly observing gorillas is difficult, and researchers traditionally have estimated gorilla densities on the basis of nest counts, combined with data on nest production and nest decay rates (Bermejo 1999; Blake et al. 1995; Blom et al. 2001; Brugiere and Sakom 2001; Carroll 1988; Fay 1989; Fay et al. 1989; Furuichi et al. 1997; Poulsen and Clark 2004; Remis 2000a; Tutin and Fernandez 1984; Williamson and Usongo 1996). The estimates are frequently extrapolated and are the basis of our present knowledge on the large-scale distribution of western gorillas.

However, the calculations involve assumptions about nest building behavior that may be invalid. For example, nest group size might not be a good estimator of ape group size; researchers might not detect all nests, and single gorillas can produce $>1$ night nest (Mehlman and Doran 2002; Remis 1993; Tutin et al. 1995). Also, many density estimates relied on a single study of nest decay rate (Tutin and Fernandez 1984), even though decay rate can show high spatiotemporal variation. Extrapolating biased nest production and decay rates over huge survey areas leads to large inaccuracies in estimates of gorilla abundance (Walsh and White 1999). Thus improved or new methods are critical for more accurate measures of gorilla distribution and abundance.

One alternative is to use dung as an index of gorilla abundance. Dung has long been an effective means to survey elusive forest species, including small animals, macropods, ungulates, and forest elephants (Barnes 2000; Barnes et al. 1997; Fuller 1991; Merz 1986; Nchanji and Plumptre 2001; Neff 1968; Plumptre and Harris 1995; Tchamba 1992; Walsh and White 1999). Gorilla dung piles are more numerous and decay faster than nests, which is more in keeping with the steady-state assumption on which researchers have based most gorilla densities (McClanahan 1986; Kuehl et al. 2007).

Previous estimates of gorilla defecation rates are few, and come mostly from captive studies of gut passage rates wherein diets are low in fiber and environmental conditions poorly resemble those in the wild (Caton 1999; Lambert 2002; Milton 1999; Remis 2000b). Schaller (1963) estimated that wild mountain gorillas defecated $\geq 5.51$ times/d; they deposited half the dung boli at or near nest sites (based on 2-d follows of 2 lone silverbacks and investigation of 4 group nest sites). The only estimate for western gorillas, whose diet differs greatly from that of mountain gorillas, was a minimum of 3-5 defecations at Lopé (Tutin et al. 1991). Rogers et al. (1998) also noted a high proportion of western gorilla dung deposited at nest sites. 
Besides small sample sizes, there was a very narrow window of environmental conditions on which to base the defecation rate estimates. One should relate the amount and timing of fecal output to feeding behavior and gut passage time (Warner 1981). Defecation rate may also vary with season (rainfall), diet (proportion of fruit vs. nonreproductive plant parts), age, and health (White and Edwards 2000).

Our aim was to provide improved daily defecation rate estimates for western gorillas. We modeled individual dung production rate to estimate the number of defecation events and dung piles produced on each observation day by habituated gorillas at Bai Hokou, Central African Republic (CAR). We also used data on fruit availability, rainfall, and a remotely sensed measure of vegetation greenness [normalized differenced vegetation Index (NDVI)] to investigate seasonal variation in daily dung production rates. Finally, we assessed the relative usefulness of counting defecation events versus counting dung piles, and evaluated the threshold distance defining when 2 dung boli are treated as different piles during surveys. Our ultimate goal is to provide less biased methods for translating transect data into gorilla density estimates.

\section{Methods}

\section{Study Site and Subjects}

Bai Hokou $\left(2^{\circ} 51^{\prime} 34^{\prime \prime} \mathrm{N}, 16^{\circ} 28^{\prime} 03^{\prime \prime} \mathrm{E}\right)$ is within the Dzanga-Ndoki National Park $\left(1240 \mathrm{~km}^{2}\right)$ in southwestern CAR. The Dzanga-Sangha Protected Areas (DSPA), a collaboration between the CAR Government, the World Wide Fund for Nature (WWF) and GFA Terra Systems consult (for the German Technical Cooperation, GTZ), manages the park, together with the Dzanga-Sangha Special Dense Forest Reserve $\left(3159 \mathrm{~km}^{2}\right)$. Bai Hokou is the base of the Primate Habituation Programme, where the habituation of gorillas for tourism has been ongoing since 1997 (Blom et al. 2004). We collected dung deposition data during follows of the well-habituated Munye group, comprising a silverback and his subadult son (ca. 6.5 yr). The Munye group regularly accepted observers at close range, allowing prolonged visibility (>80\% of 15-min scan samples: Cipolletta et al. 2007). We could accurately assign the origin of all dung piles based on dung lobe size alone (Schaller 1963).

\section{Dung Deposition: Detection for Defecation Rate}

We located the gorillas by tracking their footprints and food remains from nest to nest with the help of skilled BaAka trackers. The gorillas remained in or nearby their nests between 1800 and $0600 \mathrm{~h}$. We split tracking into morning (0700-1200 h) and afternoon (1200-1700 h) teams. We collected defecation data in 1 or both of the periods on $\geq 5 \mathrm{~d} / \mathrm{mo}$ over 10 mo from October 2003 to July 2004 .

Dung data fall into 2 categories: dung piles from directly observed defecation events and ones as traces post-event. We assumed that gorillas had just deposited all dung piles found as traces, other than those at night nests, and reduced any error in the assumption by allocation post hoc of dung piles to the hour in which we found 
them. We assumed that dung piles at nests were deposited from 0600 to $0700 \mathrm{~h}$, before the gorillas left their nests. We easily distinguished dung from the previous night or evening from morning dung by: dryness, hardness, and state of decay, including that from dung beetles. As we could not accurately determine the timing of the evening dung piles, we pooled all such dung into a single class, for which we estimated production rate separately.

For both gorillas we collected data on: 1) the time of each event or if a trace, the time of location; 2) the individual's position (ground or tree height) during direct observations; 3) habitat type: monodominant forest of Gilbertiodendron dewevrei, mixed species forest, riverine forest, forest of Marantaceae spp., light gaps, forest clearings, logging roads, and transitional phases between them; 4) dung pile height; 5) distance between different dung piles from the same event $(\geq 0.1 \mathrm{~m}) ; 6)$ minutes of direct observation per morning or afternoon sampling period.

\section{Analysis}

Modeling daily dung production rate For each individual, we estimated the number of dung piles produced during the 10 daylight observation hours heuristically by dividing the number of directly observed dung piles $(N)$ produced during a given morning by its duration ( $F$, in hours), then multiplying by the proportion of the morning in which we directly observed the focal gorilla $(O)$. We then multiplied the hourly production rate by the number of observation hours (10), to estimate a daily, diurnal production rate $\left(N_{d}\right)$

$$
N_{d}=10(O(N / F)) .
$$

We followed an analogous procedure for all afternoon sessions, then averaged $\mathrm{Nd}$ across all mornings and afternoons.

Using observed dung piles only would potentially underestimate dung production rate if we missed some dung piles deposited while gorillas were out of view. Feeding records and data on mean gut retention times of captive individuals (Caton 1999; Milton 1999; Remis 2000b; Remis and Dierenfeld 2004) indicate that peak production rate should occur mostly at night or early morning, precisely when the gorillas were out of visual contact (feeding peaks 0700-1000 h and 1300-1700 h; Fig. 1). We thus performed the same procedure using trace data instead. To accommodate trace data and allow diurnal variation in production rate we used a linear modeling approach. We started with a simple baseline model assuming that during daylight hours, gorillas produced dung piles at a constant hourly rate $(A)$. For the model, the predicted number of dung counted during a given morning or afternoon of length $T$ is

$$
N=A T O+A T(1-O) D,
$$

wherein $D$ is the probability that we detected a dung pile gorillas deposited when not in direct visual contact. We used a GLM (nonlinear regression module of SPSS version 13.0 assuming Gaussian error) to estimate values for hourly production rate, $A$, and detection probability, $D$, simultaneously from direct observation and trace data. We then multiplied by 12 to arrive at a daily dung pile production rate estimate. 


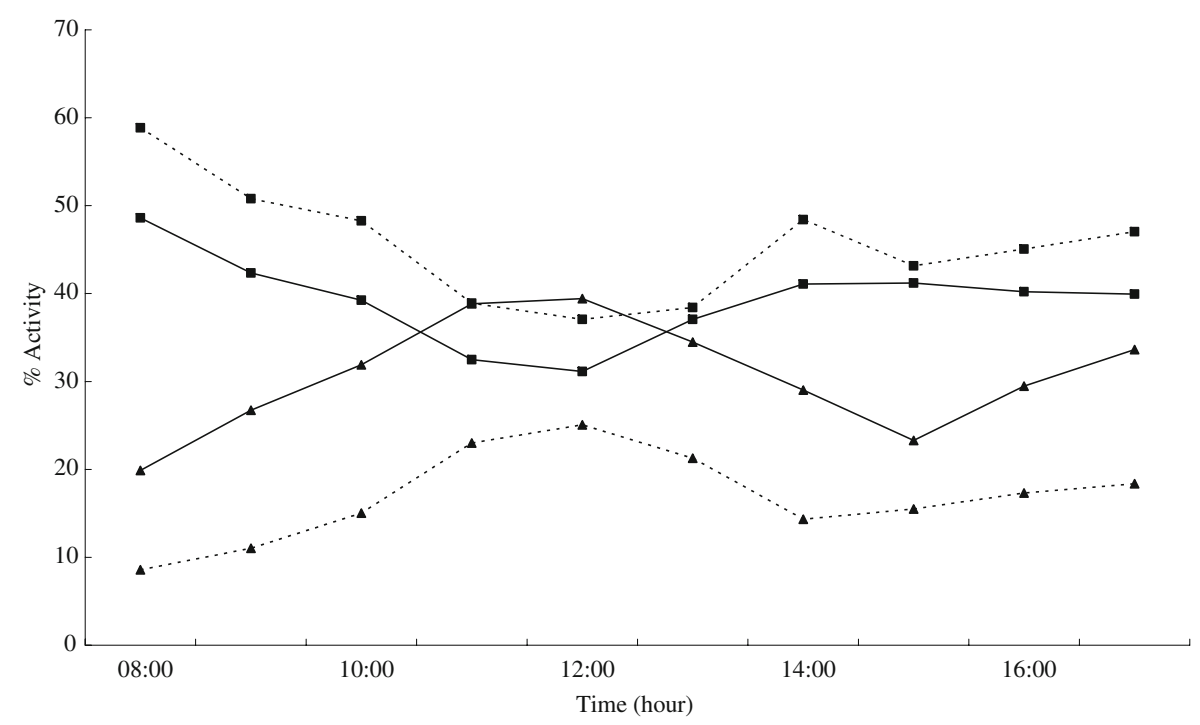

Fig. 1 Percentage frequency activity per hour per individual: solid lines, silverback; dashed lines, subadult; squares, \% time feeding; triangles \% time resting.

We used 3 approaches to represent the predicted morning peak in production rate. First, we simply fitted separate morning and afternoon dung pile production rates $\left(A_{a}\right.$ and $A_{m}$ ). Second, we assumed that for the first hour of the morning, production rate increased by an increment $(B)$ above the background production rate $(A)$. This changed our hourly defecation estimator of the morning to

$$
N=(A+B) T_{6} O+(A+B) T_{6}(1-O) D+A T_{7+} O+A T_{7+}(1-O) D
$$

wherein $T_{7+}$ is the number of follow hours after $0700 \mathrm{~h}$. Third, instead of adding a discrete increment in production rate, we assumed that for the first $3 \mathrm{~h}$ of the day production rate declined according to a Gaussian function:

$$
f(t)=A+B e^{-\frac{(t-6)^{2}}{2 s^{2}}} .
$$

This gives

$$
N=\left(A T_{9+} O+A T_{9+}(1-O) D+\Sigma_{t=6.8}(f(t) O+f(t)(1-O) D)\right),
$$

Note that in all the approaches the values of $O$, the proportion of time that gorillas were in direct visual contact, were specific to each hour or group of hours. For all 3 approaches, we considered models with all combinations of detection probability and dung production rate, including separate detection probabilities for morning and afternoon periods.

To obtain $95 \%$ confidence intervals $(\mathrm{CI})$ for each dung pile production rate estimate, we bootstrapped the data ( $N=113$ morning or afternoon sampling periods). To compare different models, we used Akaike's information criterion (AIC, Burnham and Anderson 2002). To arrive at our final estimates of dung pile production rate we averaged estimates from different models via the Akaike weight 
method. Estimates in Table III incorporate evening dung pile and defecation events, which we estimated as simple means for each individual (as in Eq. 1).

Environmental covariate modeling To explore seasonal variation in dung pile production rate, we used several environmental factors as covariates in a GLM. To reduce stochastic variation we pooled data into $10-\mathrm{d}$ sampling periods $(N=2310-\mathrm{d}$ sampling periods) and predicted the total number of dung produced during each period. The covariates were: the average number of fruit species found in daily dung samples; average daily rainfall (using sampled days only); average daily rainfall from $3 \mathrm{~d}$ previous to the day of dung sampling (reduced feeding activity during heavy rain may result in reduced fecal output 2-3 d later); total rainfall for the $10-\mathrm{d}$ period; and NDVI data (with a spatial resolution of $1 \mathrm{~km}$ and a temporal resolution of $10 \mathrm{~d}$, http://free.vgt.vito.be/). NDVI is a measure of canopy greenness correlated with rainfall, vegetation structure, and leafing phenology. Because there is often a time lag in the effect of weather on phenological patterns such as fruiting (Shinoda 1995), we also considered NDVI values from 3 mo before dung sampling.

In the GLM, we estimated daily dung output as the sum of the number of direct observations and the normalized number of trace observations, i.e., observed number divided by the detection probability from the model average, corrected for observation effort on that day and averaged over each 10-d sampling period. We implemented the covariate model via a best-subsets GLM, with a log link function and Gaussian error, in Statistica version 7.1. For each gorilla, we chose best models and evaluated the relative importance of each covariate evaluated on the basis of AIC and Akaike weight (Burnham and Anderson 2002). We examined effect sizes of highly weighted covariates by evaluating the relative dung production rates predicted by the lowest and highest observed values for a given covariate.

Dung piles vs. defecation events The fecal material produced in single defecation events does not always fall in 1 pile, particularly during defecations from trees and while moving. A method to enumerate defecation events from dung pile counts is necessary to ensure that the counts on transect surveys correspond to ones counted in dung production rate studies. The simplest approach is to define a dung pile as a cluster of fecal material that is separated from other fecal material by more than some threshold distance. Short threshold distances minimize bias arising from treating dung deposited by multiple gorillas as a single pile, but reduce estimate precision because the coefficient of variation in the number of dung piles produced per day increases as threshold distance decreases. This can confound estimates of seasonal variation in defecation rate and reduce the precision of dung production rate estimates based on covariate modeling.

Accordingly, we repeated our daily dung pile production rate and covariate modeling based on defecation rates. To convert daily defecation rates into estimates of dung pile production rates we multiplied by the mean number of dung piles produced per defecation event, which we estimated using both directly observed events and traces. To compare the precision of the covariate modeling, we considered all models within the 95\% Akaike weight confidence set. We derived standard errors (SE) for each parameter by bootstrapping the data and used the $\delta$ 
method (Seber 1982) to estimate a global SE for each model. We then calculated Akaike weight averaged SEs across models.

\section{Results}

\section{Dung Deposition}

We recorded 274 defecation events that produced 370 dung piles on 96 d (dry season $N=33 \mathrm{~d}$, wet season $N=63 \mathrm{~d}$ ), including 75 morning and 38 afternoon sampling periods. We detected more defecation events and dung piles as traces than we observed directly (Table I). Dung piles from the 2 individuals were easily distinguishable [average fresh dung height silverback (SB), $6.48 \mathrm{~cm}$, SE 0.16 and subadult (SA), $4.20 \mathrm{~cm}$, SE 0.13; Fig. 2), and similar to the dung diameters per Schaller (1963: SB $>7.3 \mathrm{~cm}$, juvenile $4-5.4 \mathrm{~cm}$ ). The proportion of average hourly follow time gorillas were in direct visual contact was greater in the afternoon and for the silverback (SB morning $=0.41$, SB afternoon=0.49, SA morning $=0.32$, SA afternoon=0.39). There was a large proportion of dung piles at nests (SB 53\%, SA $42 \%$ ). Most of themwere in Marantaceae forest (SB 69\%, SA 65\%) and non-nest dung piles were mostly in mixed forest (SB $82 \%$, SA $86 \%$ ).

\section{Heuristic Estimates of Defecation Rate}

Pooling direct observations and traces gave the silverback a higher rate for both defecation and dung pile production (Table II). Defecation rates varied diurnally for both individuals (Fig. 3). Peak morning and midday rates coincided with their departure from the night nests and the end of a rest period between 1000 and $1300 \mathrm{~h}$ (Fig. 1). Defecations were at the silverback's nest on $96 \%$ of days, but only on $35.5 \%$ of days for the subadult. Defecations from the previous evening were not so prevalent (SB $27.6 \%$ of days, SA $14.5 \%$ of days); hence evening defecation rates were low (SB 0.29 defecation events, CV 0.16, and 0.41 dung piles, CV 0.23; SA 0.16 defecations events, CV 0.24, and 0.20 dung piles, CV 0.30). When we add them to the previous estimates from daily data, total daily defecation rates are 4.51 and 3.39 for the silverback and subadult respectively, and 6.28 and 4.12 for dung pile production rates.

Table I Number of defecation events versus dung piles from direct observation and trace data

\begin{tabular}{|c|c|c|c|c|c|c|}
\hline & \multicolumn{3}{|c|}{ Defecation events } & \multicolumn{3}{|c|}{ Dung piles } \\
\hline & Direct & Trace & Total & Direct & Trace & Total \\
\hline Silverback & 38 & 132 & 170 & 41 & 194 & 235 \\
\hline Subadult & 34 & 70 & 104 & 26 & 109 & 135 \\
\hline
\end{tabular}




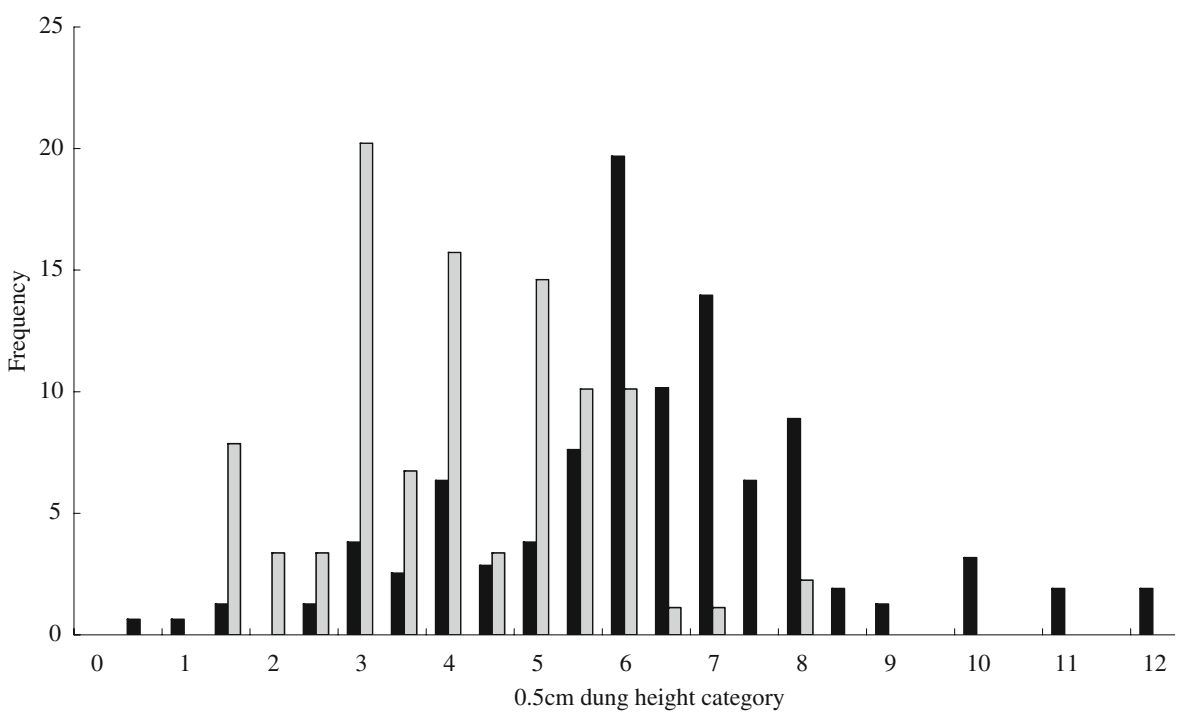

Fig. 2 Frequency of individual dung pile heights in $0.5-\mathrm{cm}$ categories: black bars, silverback; gray bars, subadult.

\section{Maximum Likelihood Modeling}

For the silverback, 3 dung pile models accounted for $93 \%$ of the Akaike weight (Table IIIa). The best fitting model ( $41 \%$ of Akaike weight) assumed a single dung pile production rate for the entire day but different detection probabilities for morning and evening. The model-averaged estimates showed little difference in dung production rate between morning and evening, but estimated a higher detection probability in the morning (Table IV). All models produced similar daily dung pile production rates, with a model-averaged estimate of $5.03 \mathrm{dung} / \mathrm{d}$ (including evening dung, 95\% CI 3.99-10.64 dung/d).

For the subadult (Table IIIb), we chose a slightly different set of models. In contrast to the heuristic approach, the model-averaged daily dung pile production rate (5.57 dung piles/d, 95\% CI 2.08-12.03 dung/d) was similar to that for the silverback. Because the heuristic method failed to correct for the subadult's much lower trace dung detection probability, it underestimated subadult dung pile production rate.

Results for the analyses based on defecation events, rather than dung piles, produced comparable results (Table IIIc and d). Defecation rate estimates for

Table II Daily defecation and dung pile production rates from direct observation and trace data

\begin{tabular}{|c|c|c|c|c|c|c|}
\hline & \multicolumn{3}{|c|}{ Defecation events } & \multicolumn{3}{|l|}{ Dung piles } \\
\hline & Direct & Trace & Pooled & Direct & Trace & Pooled \\
\hline Silverback & $1.44(30)$ & $2.77(12)$ & $4.22(12)$ & $1.83(39)$ & 4.04 (11) & $5.87(11)$ \\
\hline Subadult & $1.79(29)$ & 1.45 (17) & $3.23(18)$ & $2.11(18)$ & $2.56(16)$ & $3.92(13)$ \\
\hline
\end{tabular}

Numbers in parentheses indicate sample sizes.

Springer 


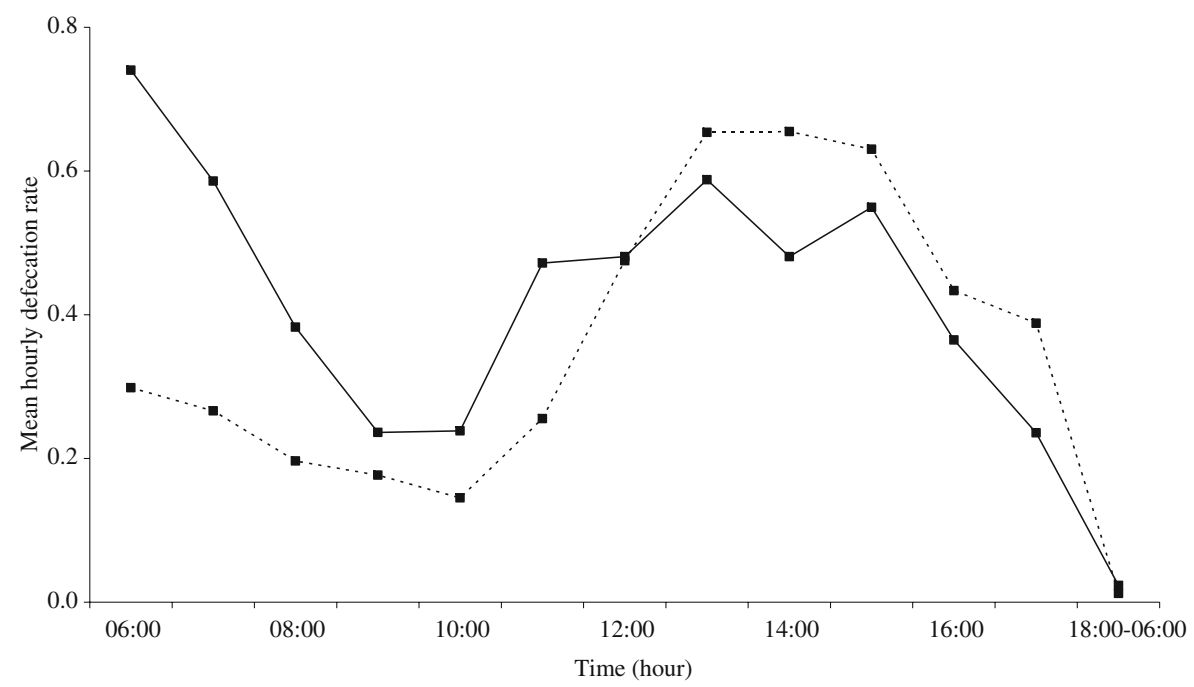

Fig. 3 Mean defecation rate per hour per individual (smoothed): solid lines, silverback; dashed lines, subadult.

Table III Estimates for the different daily and afternoon defecation ( $A$ and $A_{a}$ ) and detection probability $\left(D\right.$ and $\left.D_{a}\right)$ model parameters

\begin{tabular}{|c|c|c|c|c|c|c|}
\hline A & $\mathrm{A}_{\mathrm{a}}$ & $\mathrm{D}$ & $\mathrm{D}_{\mathrm{a}}$ & Dung/d & AIC & Cumulative Akaike wt \\
\hline \multicolumn{7}{|c|}{ a. Silverback dung pile models } \\
\hline 0.39 & & 0.96 & 0.58 & $5.14(4.27-10.24)$ & 474.14 & 0.41 \\
\hline 0.37 & & & 0.92 & $4.89(3.94-7.73)$ & 474.36 & 0.73 \\
\hline 0.42 & 0.33 & & 0.87 & $4.88(3.62-14.67)$ & 474.85 & 0.93 \\
\hline 0.38 & 0.46 & 1.00 & 0.41 & $\begin{array}{l}5.47(3.66-14.92) \\
5.03(3.99-10.64)\end{array}$ & 475.90 & 1.00 \\
\hline \multicolumn{7}{|c|}{ b. Subadult dung pile models } \\
\hline 0.35 & 0.55 & 0.31 & & $5.58(1.92-12.66)$ & 404.36 & 0.73 \\
\hline 0.28 & 0.61 & 0.52 & 0.19 & $5.56(2.56-10.98)$ & 405.64 & 0.93 \\
\hline 0.43 & & 0.20 & 0.50 & $5.34(2.43-8.43)$ & 407.00 & 0.98 \\
\hline 0.45 & & 0.25 & & $\begin{array}{l}5.65(2.14-8.66) \\
5.57(2.08-12.03)\end{array}$ & 407.98 & 1.00 \\
\hline \multicolumn{7}{|c|}{ c. Silverback defecation event models } \\
\hline 0.34 & & 0.63 & & $4.31(2.40-9.48)$ & 331.73 & 0.52 \\
\hline 0.34 & & 0.65 & 0.47 & $4.41(2.88-8.82)$ & 332.35 & 0.80 \\
\hline 0.35 & 0.32 & 0.61 & & $4.30(1.82-8.71)$ & 333.16 & 0.92 \\
\hline 0.30 & 0.40 & 0.81 & 0.32 & $\begin{array}{l}4.49(2.29-9.93) \\
4.36(2.46-9.26)\end{array}$ & 333.61 & 1.00 \\
\hline \multicolumn{7}{|c|}{ d. Subadult defecation event models } \\
\hline 0.21 & 0.39 & 0.48 & & $3.77(0.65-8.12)$ & 329.89 & 0.82 \\
\hline 0.18 & 0.41 & 0.63 & 0.42 & $3.74(1.32-8.09)$ & 331.72 & 0.95 \\
\hline 0.29 & & 0.26 & 0.85 & $3.58(1.74-7.64)$ & 332.83 & 1.00 \\
\hline 0.32 & & 0.34 & & $\begin{array}{l}3.99(1.95-9.24) \\
3.75(0.78-8.08)\end{array}$ & 340.49 & 1.00 \\
\hline
\end{tabular}

Dung/d includes evening defecation rates; confidence intervals are shown in parentheses; model averaged value at the bottom. 
Table IV Model-averaged parameter estimates for the different daily and afternoon defecation $\left(A\right.$ and $\left.A_{a}\right)$ and detection probabilities $\left(D\right.$ and $\left.D_{a}\right)$

\begin{tabular}{lllllllll}
\hline & \multicolumn{5}{c}{ Defecation event models } & \multicolumn{5}{c}{ Dung pile models } \\
\hline Parameter & $A$ & $A_{\mathbf{a}}$ & $D$ & $D_{\mathbf{a}}$ & $A$ & $A_{\mathbf{a}}$ & $D$ & $D_{\mathbf{a}}$ \\
Silverback & 0.34 & 0.34 & 0.65 & 0.56 & 0.39 & 0.38 & 0.93 & 0.73 \\
Subadult & 0.21 & 0.39 & 0.49 & 0.49 & 0.34 & 0.55 & 0.35 & 0.29 \\
\hline
\end{tabular}

different models were again similar within and between gorillas. The detection probability difference between silverback and subadult narrowed, because the higher probability of finding $\geq 1$ dung pile from an event had a greater impact for the subadult.

\section{Modeling Daily Defecation Rate with Environmental Covariates}

For both individuals, covariate models fit the data better than the assumption of constant dung pile production or defecation rate (best dung pile model $\mathrm{SB} \mathrm{AIC}=$ 88.29, null $\mathrm{AIC}=98.73$, $\mathrm{SA} \mathrm{AIC}=28.45$, null $\mathrm{AIC}=30.99$; best defecation event model SB AIC=88.41, null AIC=91.19, SA AIC=15.01, null AIC=22.04). Overall, defecation event models produced more precise estimates than dung pile models (averaged dung pile models SB $\mathrm{CV}=0.091$, SA $\mathrm{CV}=0.177$; averaged defecation event models $\mathrm{SB} C \mathrm{CV}=0.065$, SA CV $=0.084)$.

In all 4 analyses $(\mathrm{SB} \backslash \mathrm{SA} \times$ piles $\backslash$ events), the best model accounted for a large proportion of the Akaike weight. Two covariates were particularly well represented in the $95 \%$ model confidence sets: average daily rainfall and total rain for the $10-d$ period. Rainfall on the day of sampling correlates positively with both dung pile production and defecation rate, whereas rain for the entire 10-d period correlates negatively. Effect sizes for the covariates tended to be large. For the silverback's best defecation event model, predicted defecation rate was 2.37 times higher for the highest observed average daily rainfall than for the lowest. Likewise, predicted defecation rate increased by a factor of 2.41 over the observed range of $10-\mathrm{d}$ rainfalls.

\section{Number of Piles Per Defecation Event}

The distance between consecutive dung piles from the same event differed between individuals (SB mean $=0.62 \mathrm{~m}$, SE 0.010; SA mean $=0.36 \mathrm{~m}$, SE 0.010). The majority of defecation events occurred on the ground (SB 97\%, SA 80\%), most of which comprised 1 pile $\leq 0.1 \mathrm{~m}$ (SB 50\%, SA 65\%). The subadult defecated from trees more often than the silverback did (SB 3\%, SA 20\%), with a higher production of multiple-pile events from trees (SB 25\%, SA 65\%). This may be a function of sample size $(\mathrm{SB}=8, \mathrm{SA}=26)$ or height (the silverback's most frequent height when defecating from trees was $0-5 \mathrm{~m}$ whereas the subadult's was 5-10 m). Using observations and traces together gave a higher number of piles per event (observations and traces SB 1.38, SA 1.31; observations only SB 1.11, SA 1.26). 


\section{Discussion}

We confirm the potential of dung as an index of gorilla abundance. Despite diurnal variation, dung production rate estimates were fairly consistent between the subadult and silverback and similar to previous estimates based on lower sampling effort (Schaller 1963; Tutin et al. 1991). We have also shown that covariate modeling of easily collectable environmental data can explain substantial variation in defecation and dung pile production rates, thus promising to increase estimate precision and reduce bias. However, several other issues remain before one can establish dung as an index for gorilla density estimation.

\section{Seasonal Variation}

Perhaps the greatest issue is seasonal variation in defecation and dung pile production rates. Our generalized linear modeling results imply strong seasonal influences on dung production rates. For 2 of 4 best models the improvement in model fit produced by the covariates was moderately large, with AIC decreases of 10.4 and 7.1. More importantly, the effect sizes for major covariates were large, with predicted defecation and production rates more than doubling over the observed range of covariate values. Rainfall was particularly important and appeared to influence dung production rates in 2 opposing ways. First, dung production rates correlate positively with rainfall on the day of sampling. It is not clear whether this was due to an actual increase in the rate of defecation on rainy days or to an increased probability of dung detection because the gorillas moved less on rainy days. Our approach of first estimating dung detection probability, then using it to model variation in production rates did not allow us to tease apart the 2 explanations. Doing so would require customized analysis software that embedded the detection probability model within a generalized linear modeling and model selection framework. Because we wanted to make our analysis accessible and easily repeatable with available statistical software, we did not pursue such an analysis.

In contrast, dung production rates declined with increasing 10-d rainfall, which may reflect a dry season increase in rates of fiber consumption. Fiber increases gut passage rates in both chimpanzees and humans (Milton 1999) and leads to increased fecal output (Warner 1981). However, the defecation rate of forest elephants, whose diet closely resembles that of gorillas, is higher in the wet season (Ruggiero 1992). Further study is needed to investigate whether seasonal differences in defecation rates are due to changes in dietary quality or the sheer amount of food ingested.

In any case, the effects of rainfall on dung production rates imply that assuming a constant defecation rate (Barnes 2001; Barnes et al. 1997; Fuller 1991; Merz 1986; Neff 1968; Plumptre and Harris 1995; Tchamba 1992) produces biased density estimates. For example, we used transect surveys at Bai Hokou to estimate a wet season gorilla dung density of $32 / \mathrm{km}^{2}$ (Todd, unpub. data) and a daily dung decay probability of $0.28 / \mathrm{d}$ (Kuehl et al. 2007). Dividing the product of the 2 estimates by our mean dung pile production rate estimate of 5.3/d gives a gorilla density estimate of $1.7 / \mathrm{km}^{2}$. However, if we use the GLM results to predict a wet season-specific production rate of 9.2 dung piles/d, then the gorilla density estimate shifts to $0.98 / \mathrm{km}^{2}$. 
Thus, using a mean dung production rate estimate instead of a seasonally adjusted estimate biases the gorilla density estimate upward by $73.5 \%$.

\section{Detection Probability}

We highlights the difficulties inherent in collecting field data on rare behavioral events, such as defecation, even from well-habituated individuals. Theoretically, closely following focal subjects should make measuring defecation rates easy. However, researchers cannot observe many defecation events directly and may or may not detect them, leading to underestimates of dung production rates.

The problem was particularly acute for the subadult, whose smaller dung lobe size and greater tendency to defecate from trees, and from greater heights, increased the chances that we overlooked dung piles. Maximum likelihood modeling suggests that failing to account for imperfect detection probability could underestimate subadult dung pile production rate by $c a$. 30\%, which would translate into a $30 \%$ overestimation of subadult gorilla density. The models estimated much higher dung pile detection probabilities for the silverback and, consequently, less potential for overestimation of silverback density. As adult female dung lobe size and arboreality are intermediate between subadults and silverbacks, the potential for overestimating density should also be intermediate. In summary, more investigations to cover ageand sex-specific estimates of dung detection probability are required to convert dung density to gorilla density reasonably accurately.

\section{Defecation Events Versus Dung Piles}

Distinguishing between the number of defecation events and the number of detectable dung piles is important. In our study, failing to recognize that defecation events produced an average of 1.34 dung piles would lead to a $c a .31 \%$ overestimate of true gorilla numbers. Therefore, we caution against using typically overestimated defecation rates from captive individuals when converting dung encounter rates into densities. We recommend that researches using dung count studies on other species, e.g., antelopes and elephants, should also address the issue (Chapman 2004; Dhungel 1985; cf. Laing et al. 2003; Webbon et al. 2004).

The use of an appropriate threshold distance may reduce the error. Most dung piles from the same event were $\leq 10 \mathrm{~cm}$ of each other, suggesting it as a reasonable threshold distance for defining piles. Modeling defecation events, rather than dung piles, also seems to provide more precise estimates of covariate effects on dung defecation rate.

\section{Diurnal Variation}

A final issue is diurnal variability in dung production rate. Defecation patterns of hominids and most primates have a 24-h cycle: most feces are eliminated in the early morning, with a marked reduction in output during the afternoon and none during the night (this study; Caton 1999; Heaton et al. 1992; Julliot 1996; Lambert 2002). Studies that do not apply sampling designs or analyses that account for diurnal variation risk biasing their estimates. 
In conclusion, we provide the first nonanecdotal estimates of the rate at which western gorilla defecate in their natural environment. We show that one can use habituated gorillas to estimate defecation rates rigorously and that season has a strong effect on defecation rate, which one can control for via environmental covariate modeling. Still, confidence intervals on production rates were large and estimates were based on only 2 individuals. Therefore, we encourage more studies that include both more individuals and all sex/age classes.

Also meriting further study is the effect of habitat variation on defecation rate. Given that defecation rate varies with diet, it seems likely that spatial variation in distribution of food species is linked to variation in defecation rate. Unfortunately, there are very few western gorilla groups that are well-enough habituated for accurate defecation rate estimation. Therefore, it will be impossible to estimate defecation rates that are particular to the habitat distribution at each and every survey site. Instead, the best option would be to use data on observed habitat variation within and among habituated groups to estimate a habitat model similar to the rainfall model we described. The accuracy of such an endeavor will depend on the extent to which researchers can group habitats into a small number of generic classes that accurately capture the mechanistic relationship between habitat type and gorilla defecation rate. Whether this will be ultimately possible is an empirical question that can be answered only by applying well-defined estimation and model validation methods to more extensive empirical data.

Finally, the issue of spatiotemporal variation in production rates is not particular to dung, but equally applicable to other signs of subject abundance, though researchers have largely ignored it in the case of ape sleeping nests. It is vital to resolve the issue in a timely fashion to estimate gorilla population sizes accurately and to detect how fast populations are declining in order to plan effective conservation interventions.

Acknowledgments We thank Primate Habituation Program of the Dzanga-Sangha Protected Areas and all the BaAka trackers, local assistants, and student volunteers who assisted with the project; the Ministries of National and Higher Education, and Enviromment, Water, Forests, Hunting and Fishing of the Central African Republic Government; Christophe Boesch; the Max Planck Institute for Evolutionary Anthropology for institutional and financial support; the Rufford Foundation for additional funding; and Martha Robbins, Roger Mundry, and anonymous reviewers for useful comments on the manuscript.

Open Access This article is distributed under the terms of the Creative Commons Attribution Noncommercial License which permits any noncommercial use, distribution, and reproduction in any medium, provided the original author(s) and source are credited.

\section{References}

Barnes, R. F. W. (2001). How reliable are dung counts for estimating elephant numbers. African Journal of Ecology, 39, 1-9.

Barnes, R. F. W., Beardsley, K., Michelmore, F., Barnes, K. L., Alers, M. P. T., \& Blom, A. (1997). Estimating forest elephant numbers with dung counts and a geographic information system. Journal of Wildlife Management, 61, 1384-1393.

Bermejo, M. (1999). Status and conservation of primates in Odzala National Park, Republic of Congo. Oryx, 33, 323-331. 
Bermejo, M., Rodríguez-Teijeiro, J. D., Illera, G., Barroso, A., Vilà, C., \& Walsh, P. D. (2006). Ebola outbreak killed 5000 Gorillas. Science, 314, 1564.

Blake, S., Rogers, E., Fay, M. J., Ngangoue, M., \& Ebeke, G. (1995). Swamp gorillas in northern Congo. African Journal of Ecology, 33, 285-290.

Blom, A., Almasi, A., Heitkonig, I. M. A., Kpanou, J.-B., \& Prins, H. H. T. (2001). A survey of the apes in the Dzanga-Ndoki National Park, Central African Republic: A comparison between the census and survey methods of estimating the gorilla (Gorilla gorilla gorilla) and chimpanzee (Pan troglodytes) nest group density. African Journal of Ecology, 39, 98-105.

Blom, A., Cipolletta, C., Brunsting, A. M. H., \& Prins, H. H. T. (2004). Behavioral responses of gorillas to habituation in the Dzanga-Ndoki National Park, Central African Republic. International Journal of Primatology, 25, 179-196.

Brugiere, D., \& Sakom, D. (2001). Population density and nesting behavior of lowland gorillas (Gorilla gorilla gorilla) in the Ngotto forest, Central African Republic. Journal of Zoology London, 255, 251259.

Burnham, K. P., \& Anderson, D. R. (2002). Model selection and inference: A practical informationtheoretic approach. New York: Springer.

Carroll, R. W. (1988). Relative density, range extension, and conservation potential of the lowland gorilla (Gorilla g. gorilla) in the Dzanga-Sangha region of southwestern Central African Republic. Mammalia, 52, 309-323.

Caton, J. M. (1999). A preliminary report on the digestive strategy of the western lowland gorilla. Australasian Primatology, 13, 2-7.

Chapman, N. G. (2004). Faecal pellets of Reeve's muntjac, Muntiacus reevesi: Defecation rate, decomposition period, size and weight. European Journal of Wildlife Research, 50, 141-145.

Cipolletta, C., Spagnoletti, N., Todd, A. F., Robbins, M. M., Cohen, H., \& Pacyna, S. (2007). Termite feeding by western lowland gorillas (Gorilla gorilla gorilla) at Bai Hokou, Central African Republic. International Journal of Primatology, 28, 457-476.

Dhungel, S. K. (1985). Defecation rate of hog deer in captivity. Journal of Wildlife Management, 49, 925-926.

Fay, M. J. (1989). Partial completion of a census of the western lowland gorilla (Gorilla g. gorilla (Savage and Wyman)) in southwestern Central African Republic. Mammalia, 53, 203-215.

Fay, M. J., Agnagna, M., Moore, J., \& Oko, R. (1989). Gorillas (Gorilla gorilla gorilla) in the Likouala swamp forests of north central Congo: Preliminary data on populations and ecology. International Journal of Primatology, 10, 477-486.

Fuller, T. K. (1991). Do pellet count index white-tailed deer numbers and population change? Journal of Wildlife Management, 55, 393-396.

Furuichi, T., Inagaki, H., \& Angoue-Ovono, S. (1997). Population density of chimpanzees and gorillas in the Petit Loango Reserve, Gabon: Employing a new method to distinguish between nests of the two species. International Journal of Primatology, 18, 1029-1046.

Heaton, K. W., Radvan, J., Cripps, H., Mountford, R. A., Braddon, F. E. M., \& Hughes, A. O. (1992). Defecation frequency and timing, and stool form in the general-population-a prospective-study. Gut, $33,818-824$.

Julliot, C. (1996). Seed dispersal by red howling monkeys (Aloutta seniculus) in the tropical rain forest of French Guiana. International Journal of Primatology, 17, 239-258.

Kuehl, H. S., Todd, A. F., Boesch, C., \& Walsh, P. D. (2007). Manipulating decay time for efficient largemammal density estimation: Gorillas and dung height. Ecological Applications, 17, 2403-2414.

Laing, S. E., Buckland, S. T., Burn, R. W., Lambie, D., \& Amphlett, A. (2003). Dung and nest surveys: Estimating decay rates. Journal of Applied Ecology, 40, 1102-1111.

Lambert, J. E. (2002). Digestive retention times in forest guenons (Cercopithicus spp.) with reference to chimpanzees (Pan troglodytes). International Journal of Primatology, 23, 1169-1185.

McClanahan, T. R. (1986). Quick population survey method using faecal droppings and steady state assumption. African Journal of Ecology, 24, 37-39.

Mehlman, P. T., \& Doran, D. M. (2002). Influencing western gorilla nest construction at Mondika Research Center. International Journal of Primatology, 23, 1257-1285.

Merz, G. (1986). Counting elephants (Loxodonta africana cyclotis) in tropical rain forests with particular reference to Tai National Park, Ivory Coast. African Journal of Ecology, 24, 61-68.

Milton, K. A. (1999). A hypothesis to explain the role of meat-eating in human evolution. Evolutionary Anthropology, 8, 11-20.

Nchanji, A. C., \& Plumptre, A. J. (2001). Seasonality in elephant dung decay and implications for censusing and population monitoring in south-western Cameroon. African Journal of Ecology, 39, 24-32. 
Neff, D. J. (1968). The pellet-group count technique for big game trend, census, and distribution: A review. Journal of Wildlife Management, 32, 597-614.

Plumptre, A. J., \& Harris, S. (1995). Estimating the biomass of large mammalian herbivores in a tropical montane forest: A method of faecal counting that avoids assuming a 'steady state' system. Journal of Applied Ecology, 32, 111-122.

Poulsen, J. R., \& Clark, C. J. (2004). Densities, distributions, and seasonal movements of gorillas and chimpanzees in swamp forest in northern Congo. International Journal of Primatology, 25, 285-306.

Remis, M. J. (1993). Nesting behavior of lowland gorillas in the Dzanga-Sangha Reserve, Central African Republic: Implications for population estimates and understandings of group dynamics. Tropics, 294, 245-255.

Remis, M. J. (2000a). Preliminary assessment of the impacts of human activities on gorillas Gorilla gorilla gorilla and other wildlife at Dzanga-Sangha Reserve, Central African Republic. Oryx, 34, 5665.

Remis, M. J. (2000b). Initial studies on the contributions of body size and gastrointestinal passage rates of dietary flexibility among gorillas. American Journal of Physical Anthropology, 112, 171-180.

Remis, M. J., \& Dierenfeld, E. S. (2004). Digesta passage, digestibility and behavior in captive gorillas under two dietary regimens. International Journal of Primatology, 25, 825-845.

Rogers, M. E., Voysey, B. C., McDonald, K. E., Parnell, R. J., \& Tutin, C. E. G. (1998). Lowland gorillas and seed dispersal: The importance of nest sites. American Journal of Primatology, 45, 45-68.

Ruggiero, R. G. (1992). Seasonal forage utilization by elephants in central Africa. African Journal of Ecology, 30, 137-148.

Sabater Pi, G., \& Lassaletta de, L. (1958). Beitrag zu kenntnis des flaschland gorillas (Gorilla gorilla, Savage und Wyman). Zeitschrift für Saugetierk, 23, 108-114.

Schaller, G. B. (1963). The mountain gorilla: Ecology and behavior. Chicago: University of Chicago Press.

Seber, G. A. F. (1982). The estimation of animal abundance and related parameters. New York: Macmillan.

Shinoda, M. (1995). Seasonal phase lag between rainfall and vegetation activity in tropical Africa as revealed by NOAA satellite data. International Journal of Climatology, 15, 639-656.

Tchamba, M. N. (1992). Defecation by the African forest elephant (Loxodonta africana cyclotis) in the Santchou reserve, Cameroon. Mammalia, 56, 155-158.

Tutin, C. E. G., \& Fernandez, M. (1984). Nationwide census of gorilla (Gorilla g. gorilla) and chimpanzee (Pan t. troglodytes) populations in Gabon. American Journal of Primatology, 6, 313-336.

Tutin, C. E. G., Parnell, R. J., White, L. J. T., \& Fernandez, M. (1995). Nest building by lowland gorillas in the Lopé Reserve, Gabon: Environmental influences and implications for censusing. International Journal of Primatology, 16, 53-76.

Tutin, C. E. G., Williamson, E. A., Rogers, M. E., \& Fernandez, M. (1991). A case of a plant-animal relationship: Cola Lizae and lowland gorillas in the Lope Reserve, Gabon. Journal of Tropical Ecology, 69, 751-763.

Walsh, P. D., Abernethy, K. A., Bermejo, M., Beyersk, R., De Wachter, P., Akou, M. E., et al. (2003). Catastrophic ape decline in western equatorial Africa. Nature, 422, 611-614.

Walsh, P. D., \& White, L. J. T. (1999). What it will take to monitor forest elephant populations. Conservation Biology, 13, 1194-1202.

Warner, A. C. I. (1981). Rate of passage of digesta through the gut of mammals and birds. Nutrition Abstracts Review B, 51, 789-820.

Webbon, C. C., Baker, P. J., \& Harris, S. (2004). Faecal density counts for monitoring changes in red fox numbers in rural Britain. Journal of Applied Ecology, 41, 768-779.

White, L. J. T., \& Edwards, A. (2000). Methods for assessing the status of animal populations. In Conservation Research in the African Rain Forests: A Technical Handbook (pp. 218-268). Libreville: Wildlife Conservation Society.

Williamson, L., \& Usongo, L. (1996). Survey of gorillas Gorilla gorilla gorilla and chimpanzees Pan Troglodytes in the Reserve de Faune Dja, Cameroon. African Primates, 2, 67-72. 